\title{
Copper Nanoparticles Supported on a Schiff base-Fullerene as Catalyst for Reduction of Nitrophenols and Organic Dyes
}

\author{
Serkan Dayan* \\ Drug Application and Research Center, Erciyes University, 38039 Kayseri, Turkey \\ *serkandayan@erciyes.edu.tr \\ *Orcid No: 0000-0003-4171-7297
}

Received: 26 May 2020

Accepted: 14 September 2020

DOI: 10.18466/cbayarfbe.742711

\begin{abstract}
The $N$-(3-((2-hydroxybenzylidene)amino)phenyl)benzamide Schiff base ligand (L) was synthesized and characterized. The ligand was immobilized on the fullerene material with a reduction copper material. The resulting nanocomposite $\mathrm{Cu} /$ Ligand@Fullerene $\left(\mathbf{M}_{1}\right)$ was characterized by FE-SEM EDX, EDX mapping, FT-IR, and XRD techniques and tested as a catalyst for reduction of nitrophenols (2-nitrophenol (2-NP), 4-nitrophenol (4-NP)) and organic dyes (methylene blue (M.B.), Rhodamine B (Rh B)) under ambient temperature in water. The catalytic conversions and the reaction rate constant per total weight of the $\mathbf{M}_{1}$ catalyst were recorded as $89.9 \%$ at $300 \mathrm{~s}$ for 2-nitrophenol, $97.9 \%$ at $300 \mathrm{~s}$ for 4 -nitrophenol, $90.6 \%$ at $360 \mathrm{~s}$ for Rhodamine B, and $98.3 \%$ at $60 \mathrm{~s}$ for methylene blue. For 4-NP, the reusability study was carried out as five cycles between $97.9 \%$ - 87.3\% conversions, respectively. The fabricated $\mathrm{Cu} /$ Ligand $@$ Fullerene (M) nanocomposite has good catalytic efficiency and reusability, low cost, and easy to produce.
\end{abstract}

Keywords: Copper nanoparticle, Schiff base, Reduction, Nitrophenol, Organic Dyes.

\section{Introduction}

Nitro compounds and organic dyes are currently used in many industries and pose a serious threat to environmental pollutants and the phenomenon of disposal of these wastes stands out as a serious situation. Also, amino compounds formed by the reduction of these compounds can be used as starting or intermediate chemicals in many application areas [1-3]. These application areas can be listed as chelating agents in pharmaceuticals, polymers, pesticides, explosives, fibers, dyes, and cosmetics, etc. [4-10]. The reduction reactions are among the frequently used reactions as in the past. To provide better catalytic conditions in the reduction reactions, both the efficiency of the catalyst must be good, and it can be easily produced. In this context, many metals (copper [11], cobalt [12], palladium [13], ruthenium [3], silver [14], nickel [15], etc.) have been used as catalysts in nanoparticle reduction reactions. Copper nanoparticles can be seen as preferred materials in many aspects especially in recent years $[16,17]$. Copper nanomaterials, which are also frequently used in immobilization processes, are also widely used as catalysts $[18,19]$. The catalysts obtained from the immobilization of copper nanoparticles with
Schiff base ligands have also been used in reduction reactions and the successful results have been obtained $[20,21]$. Both Schiff base compounds and the copper nanoparticles are often preferred because they are easy to manufacture, synthesize with high yields, and are readily available. In this work, the Cu/Ligand@Fullerene ( $\left.\mathbf{M}_{1}\right)$ nanocomposite was fabricated with immobilization methodology as a catalyst by fullerene support material, Schiff base ligand, and copper nanoparticles. The nanocomposite $\mathbf{M}_{1}$ was used in the reduction of nitrophenols and some organic dyes under ambient temperature with $\mathrm{NaBH}_{4}$ as a hydrogen source in water. The catalytic results were quite promising for this type of nanocomposite in the reduction reactions.

\section{Materials and Methods}

All the chemicals and solvents were purchase from chemical manufacturers. In the FT-IR analysis was used a Perkin Elmer 400 FT-IR/FT-FIR Spectrometer Spotlight 400 Imaging System to confirm the molecular interaction between Fullerene and ligand and reduced copper nanoparticles. For NMR analyses was used a Bruker 400. The FE-SEM, EDX, and mapping employed a Zeiss GeminiSEM 500 for surface morphological characterization and mapping analysis. 
X-ray diffraction (Malvern panalytical XRD) was used to confirm for immobilization and reduction methodology. The UV-vis spectrophotometer (Shimadzu UV-2700) measurements were used for monitoring the reduction of nitrophenols and dyes.

\subsection{Experimental}

\subsubsection{Synthesis of Schiff base ligand (L)}

In a typical reaction, the 1,3-diaminobenzene $(0.25$ mmol) and benzoyl chloride $(0.25 \mathrm{mmol})$ compounds were reacted in THF $(10 \mathrm{ml})$. After the reaction, the mixture was filtered-dried and added to 2-hydroxybenzaldehyde $(0.25 \mathrm{mmol}$ in methyl alcohol $(15 \mathrm{ml})$ was stirred for Schiff base ligand formation overnight. After the process, the solvent was removed by a vacuum system. The residue was dissolved in ethyl alcohol (5 $\mathrm{ml}$ ) and the microcrystalline product in the refrigerator was filtered off and dried in the vacuum system (Figure$1)$.

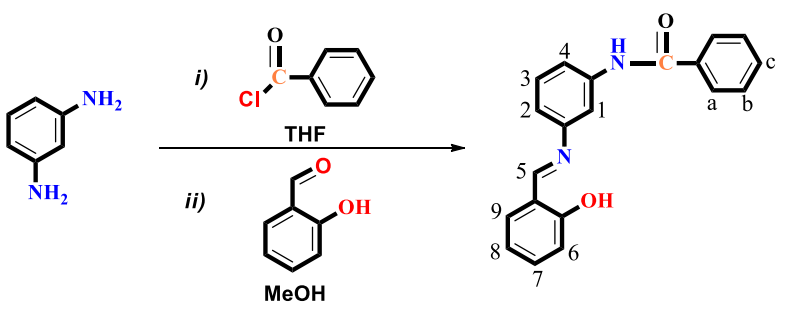

Figure-1. The numbering synthesis scheme for Schiff base ligand (L).

\subsubsection{Founded Data for the ligand For Schiff base ligand (L)}

$N$-(3-((2-hydroxybenzylidene)amino)phenyl)benzamide: Color: Yellow. Yield: $73 \%$. ${ }^{1} \mathbf{H}-\mathrm{NMR}\left(\mathrm{CDCl}_{3}, \boldsymbol{\delta}\right.$ ppm): $6.94-7.50\left(6 \mathrm{H},-H_{c},-H_{7},-H_{6},-H_{4},-H_{3},-H_{2}\right), 7.53$ (d, $\left.2 \mathrm{H}, J=8 \mathrm{~Hz},-H_{a}\right), 7.58\left(\mathrm{~d}, 2 \mathrm{H}, J=8 \mathrm{~Hz},-H_{8,9}\right), 7.80$ $\left(\mathrm{s}, 1 \mathrm{H},-H_{l}\right), 7.90\left(\mathrm{~d}, 2 \mathrm{H}, J=8 \mathrm{~Hz},-H_{b}\right), 8.68(\mathrm{~s}, 1 \mathrm{H},-$ $\left.H_{5}\right), 13.19(1 \mathrm{H},-\mathrm{OH}) \cdot{ }^{13} \mathbf{C}-\mathbf{N M R}\left(\mathbf{C D C l}_{\mathbf{3}}, \mathbf{p p m}\right): 112.5$, $117.3,117.9,118.3,119.2,119.9,127.0\left(-C_{a}\right), 128.9$ ($\left.C_{b}\right), 129.9,132.1,132.5,133.4,134.7,139.0,149.3$, $161.2,163.2(-\mathrm{N}=C H), 165.8(-C=\mathrm{O})$. FT-IR $\left(\mathbf{c m}^{-1}\right)$ : 3308, 3127, 3106, 3083, 3057, 3038, 3010, 2986, 2938, 2881, 1647, 1620, 1596, 1574, 1525, 1490, 1479, 1456, $1447,1430,1403,1359,1315,1303,1294,1277,1259$, $1215,1201,1180,1155,1150,1113,1087,1074,1026$, $1002,983,963,924,909,886,861,852,837,800,793$, 756, 711, 690, 678, 655, 608, 582, 572, 551, 541, 510, 485, 472. ESI-MS (-) (m/z): 316.200 (calc: 316.121 ).

\subsubsection{Fabrication of Cu/Ligand@Fullerene nanocomposite $\left(\mathrm{M}_{1}\right)$}

The synthesis process of Cu/Ligand@Fullerene nanocomposite $\left(\mathbf{M}_{1}\right)$ materials followed the route: $20 \%$ (w/w) of ligand and $80 \%(\mathrm{w} / \mathrm{w})$ of Fullerene (C60) as adsorbent material was added to a schlenk tube $(25 \mathrm{ml})$ as separately with organic solvent media (2-propanol / diethyl ether, 5 / 1) and sonicated for 3 hours to form a stable suspension. Then, the organic solvents were removed by the vacuum system, and the residue was dissolved again with methyl alcohol $(10 \mathrm{ml})$ and added to $\mathrm{CuCl}_{2} \cdot 2 \mathrm{H}_{2} \mathrm{O}(20 \mathrm{mg})$ and $\mathrm{NaBH}_{4}$ as a reducing agent [22]. The mixture was stirred and sonicated for 3 hours to a stable form. Also, the precipitated materials were subjected to the following operations in sequence: filtering, washing with methanol and water and drying process at ambient temperature (Figure-2). After that, the nanocomposite was characterized by FT-IR, XRD, and FE-SEM-EDX and mapping.

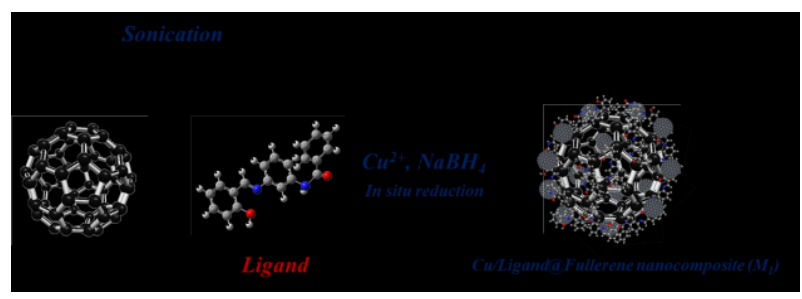

Figure-2. Fabrication of $\mathrm{Cu} /$ Ligand@Fullerene nanocomposite (M1).

\subsubsection{Catalytic Reduction of Nitrophenols and Organic Dyes}

The catalytic efficiency of $\mathbf{M}_{\mathbf{1}}$ was examined for the reduction of 2-nitrophenol, 4-nitrophenol, methylene blue, rhodamine $\mathrm{B}$ in the presence of $\mathrm{BH}_{4}^{-}$ion as a hydrogen source in the aqueous solution at ambient temperature. In a typical reaction, $2.5 \mathrm{mg}$ of the $\mathbf{M}_{1}$ catalyst was added to nitrophenols and dyes and $\mathrm{NaBH}_{4}$ (0.03 M, freshly, optimum concentration $[12,23])$ in water $(10 \mathrm{ml})$ at ambient temperature and stirred for a period of the desired time. Importantly, the catalytic reaction started instantly after the addition of the catalyst. At the end of the catalytic period followed, the reaction samples are taken from the reaction and filtered through the micro-column with cotton. The catalytic efficiency of the $\mathbf{M}_{1}$ catalyst was seen by comparing the bands which appeared and disappeared after reduction on the UV-vis spectrum.

\section{Results and Discussion \\ 3.1. Characterizations}

The fabrication process of $\mathrm{N}$-(3-((2hydroxybenzylidene)amino)phenyl)benzamide (L) and $\mathrm{Cu}$ /Ligand@Fullerene ( $\mathbf{M}_{\mathbf{1}}$ ) compounds were explained in the Figure-1 and experimental section.

In the FT-IR spectra of the bare fullerene were observed the specific $1427,1180,960,738,574,524 \mathrm{~cm}^{-1}$ peaks. For the ligand, the $\mathrm{O}-\mathrm{H}$, the aromatic $\mathrm{C}-\mathrm{H}$, the aliphatic $-\mathrm{C}-\mathrm{H}$ stretching, the $-\mathrm{C}=\mathrm{O}$ bond, and the $-\mathrm{CH}=\mathrm{N}$ - bond vibrations were aligned at $3308,3127-3106,3010-$ 2881, 1647, and 1620, respectively. Also, the peaks of the FT-IR spectrum belonging to Cu/Ligand@Fullerene (M1) was founded as 3662, 2987, 2971, 2901, 1644, 
$1601,1518,1472,1449,1406,1394,1382,1323,1250$, 1242, 1230, 1181, 1075-1066-1057 (Cu-OH-), 1028, $897(\mathrm{CuO}), 892,793,710,693(\mathrm{CuO}), 575,525,502$, 493, 471, $459 \mathrm{~cm}^{-1}$. When the spectrum of nanocomposite was examined, the presence of peaks originating from both ligand and fullerene structure was determined and the comparative spectrums are given in Figure-3.

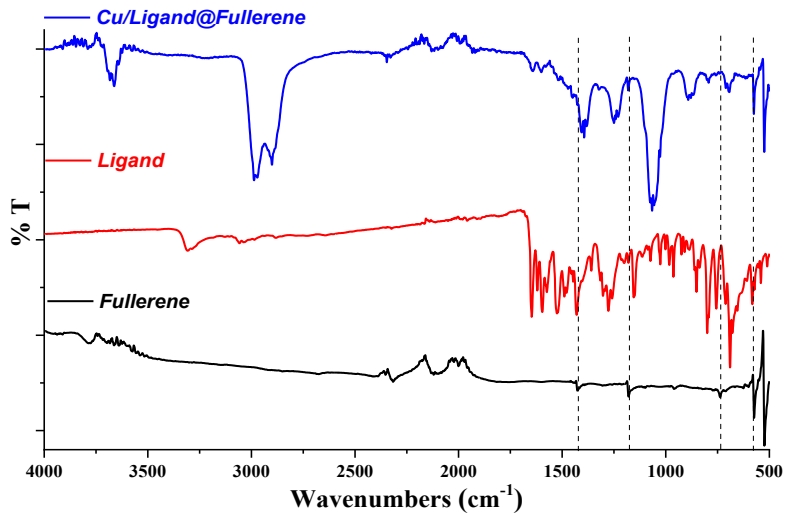

Figure-3. FT-IR comparative spectra of Fullerene, Ligand, and $\mathrm{Cu} /$ Ligand@Fullerene nanocomposite (M1).

The XRD peaks and (hkl) of bare fullerene (C60) were observed as $10.79^{\circ}(111), 17.67^{\circ}(220), 20.74^{\circ}(311)$,

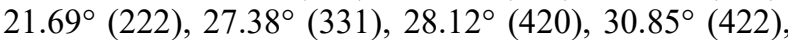
$32.79^{\circ}$ (511). For Cu/Ligand@Fullerene nanocomposite $\left(\mathbf{M}_{1}\right)$, the XRD peaks were founded as $6.61^{\circ}, 9.00^{\circ}$, $10.76^{\circ}$ (Fullerene-111), $12.21^{\circ}, 13.81^{\circ}, 14.70^{\circ}, 17.67^{\circ}$ (Fullerene-220), 19.56 ${ }^{\circ}, 20.74^{\circ}$ (Fullerene-311), $21.69^{\circ}$ (Fullerene-222), 23.37 $, \quad 25.13^{\circ}, \quad 25.49^{\circ}, \quad 27.41^{\circ}$ (Fullerene-331), $28.12^{\circ} \quad$ (Fullerene-420), $30.82^{\circ}$ (Fullerene-422), $32.77^{\circ}$ (Fullerene-511), 35.63, 37.05, $41.64^{\circ}, 42.30^{\circ}, 45.74^{\circ}$.

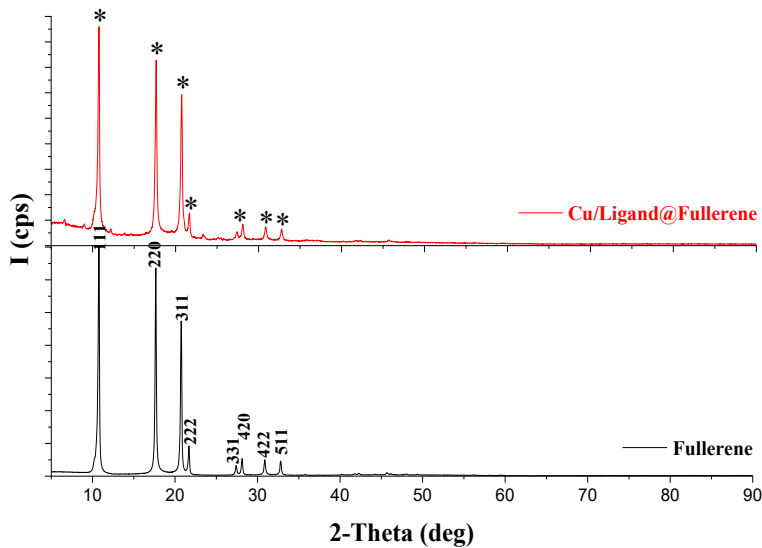

Figure-4. XRD comparative patterns of Fullerene, $\mathrm{Cu} /$ Ligand@Fullerene nanocomposite $\left(\mathbf{M}_{\mathbf{1}}\right)$.

According to the obtained XRD pattern data, the fabricated nanocomposite contains characteristic peaks originating from fullerene as well as peaks originating from ligand and metal was founded (Figure-4).

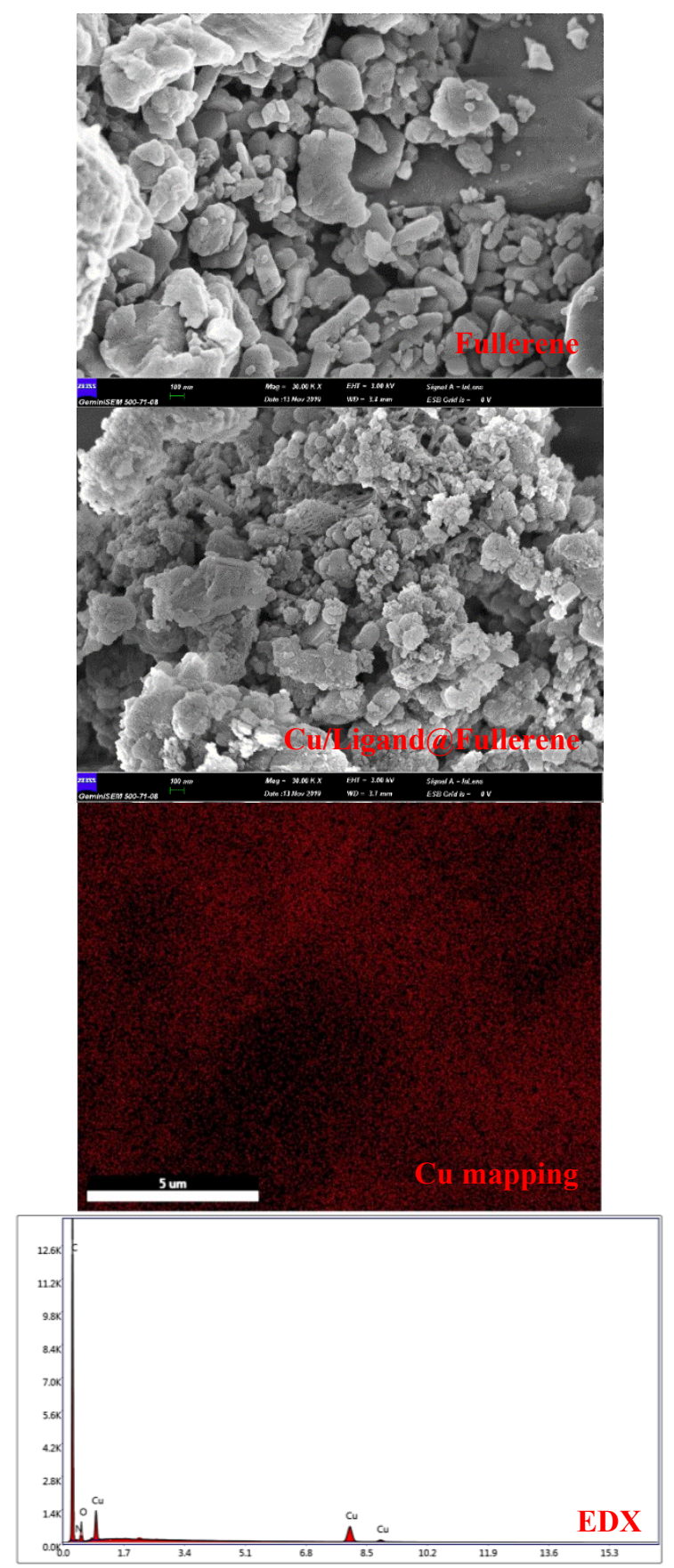

Figure-5. SEM-EDX (30.00 KX) analysis and copper mapping images of $\mathrm{Cu} /$ Ligand@Fullerene nanocomposite $\left(\mathbf{M}_{\mathbf{1}}\right)$.

The FE-SEM, EDX, and $\mathrm{Cu}$ mapping analysis of $\mathrm{Cu} /$ Ligand@Fullerene nanocomposite $\left(\mathbf{M}_{1}\right)$ was achieved, and the surface morphologies and elemental images are given in Figure-5. The surface structures of the bare fullerene and $\mathbf{M}_{\mathbf{1}}$ nanocomposite $(30.00 \mathrm{KX}$ zoom) are similar, but the material deposits from ligand and copper on the fullerene layers were observed. The presence of copper metal $(\mathrm{Cu}$ weight: $\approx 7.00 \%$ with EDX analysis) dispersed Cu/Ligand@Fullerene nanocomposite $\left(\mathbf{M}_{\mathbf{1}}\right)$ was approved by the EDX and copper mapping methods. Each sheet was shown to 
have a length of $20-500 \mathrm{~nm}$. The surface analyses show that the immobilization and metal reduction process was successfully performed (Figure-5).

\subsection{Catalytic Studies}

We investigated the catalytic efficiency of $\mathbf{M}_{\mathbf{1}}$ nanocomposite by using the reduction of 2-nitrophenol (2-NP), 4-nitrophenol (4-NP) as nitrobenzenes, methylene blue, and rhodamine $\mathrm{B}$ as organic dyes in the presence of $\mathrm{NaBH}_{4}$ in the water at ambient temperature. The catalytic reaction was monitored spectrophotometrically due to the 2-nitrophenol (2-NP) reactant and product having different absorption bands such as $\lambda_{\max }=414 \mathrm{~nm}\left(-\mathrm{NO}_{2}\right.$ group of 2-NP). Firstly, the 2-nitrophenol $\left(5 \times 10^{-4} \mathrm{M}\right)$ mixture has a yellow colour which is the colour of the adsorption band belonging to the 2-nitrophenolate, this colour gradually vanished because of the formation of the 2-aminophenol and the catalytic conversions were seen at different times between $30 \mathrm{~s}$ to $300 \mathrm{~s}$. The catalytic activity of $\mathbf{M}_{1}$ nanocomposite was achieved as $34.2 \%, 73.1 \%$, and $89.9 \%$ at the end of 30,90 , and 300 s, respectively (Figure-6).

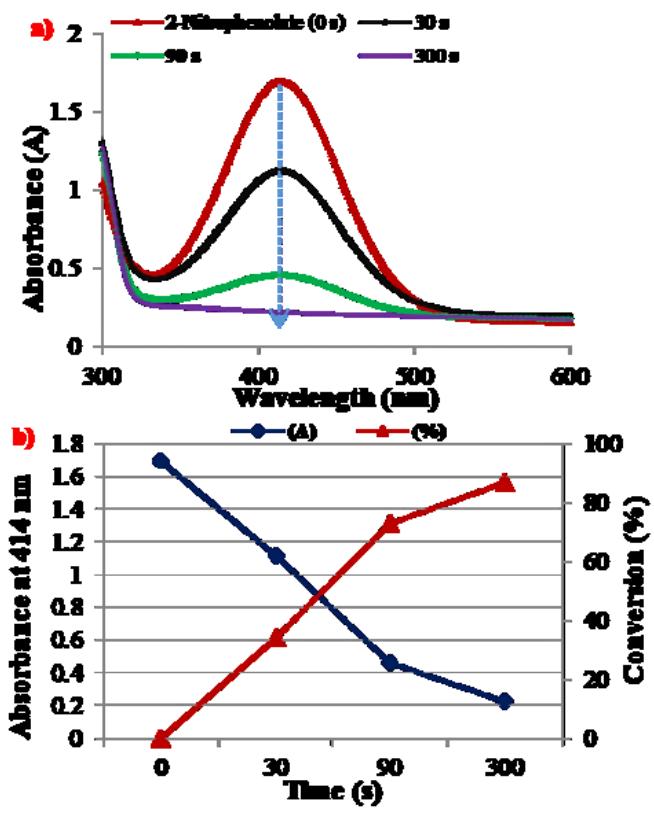

Figure-6. Time-dependent UV-vis absorption spectra of the 2-nitrophenol $\left(5.0 \times 10^{-4} \mathrm{M}\right)$ reduced by $\mathrm{NaBH}_{4}$ catalyzed by the $\mathbf{M}_{1}$ nanocomposite (a) UV-vis spectra, b) Absorbance-Conversion curve).

We have also worked the reduction of 4-nitrophenol $\left(2.5 \times 10^{-4} \mathrm{M}, 4-\mathrm{NP}\right)$ by $\mathbf{M}_{1}$ nanocomposite under likewise reaction conditions. The absorption band of the 4-nitrophenolate arises at $398 \mathrm{~nm}$ from the $-\mathrm{NO}_{2}$ (nitro) group to $-\mathrm{NH}_{2}$ (amine) group. The catalytic conversion results were obtained to be $51.2 \%$ (30 s), 59.1\% (90 s), 97.9\% (300 s) for $\mathbf{M}_{1}$ nanocomposite (Figure-7).

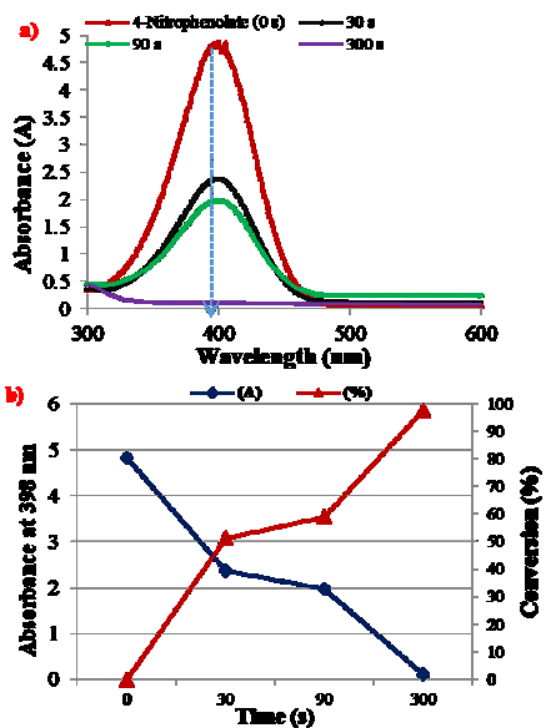

Figure-7. Time-dependent UV-vis absorption spectra of the 4-nitrophenol $\left(2.5 \times 10^{-4} \mathrm{M}\right)$ reduced by $\mathrm{NaBH}_{4}$ catalyzed by the $\mathbf{M}_{1}$ nanocomposite (a) UV-vis spectra, b) Absorbance-Conversion curve).

Moreover, the $\quad \mathrm{Cu} /$ Ligand@Fullerene $\quad \mathbf{M}_{1}$ nanocomposite was used as catalysts for the reduction of some dyes (methylene blue (MB) and rhodamine $\mathrm{B}$ ) under the optimized conditions. The adsorption band disappeared after reduction at $664 \mathrm{~nm}$ for $\mathrm{MB}, 550 \mathrm{~nm}$ for Rhodamine $\mathrm{B}$. The catalytic conversions were founded as $91.6 \%$ (30 s), 98.3\% (60 s) for MB dye, $67.3 \% \quad(120 \mathrm{~s}), 83.5 \%$ (240 s), 90.6\% (360 s) for Rhodamine B (Figure-8,9).
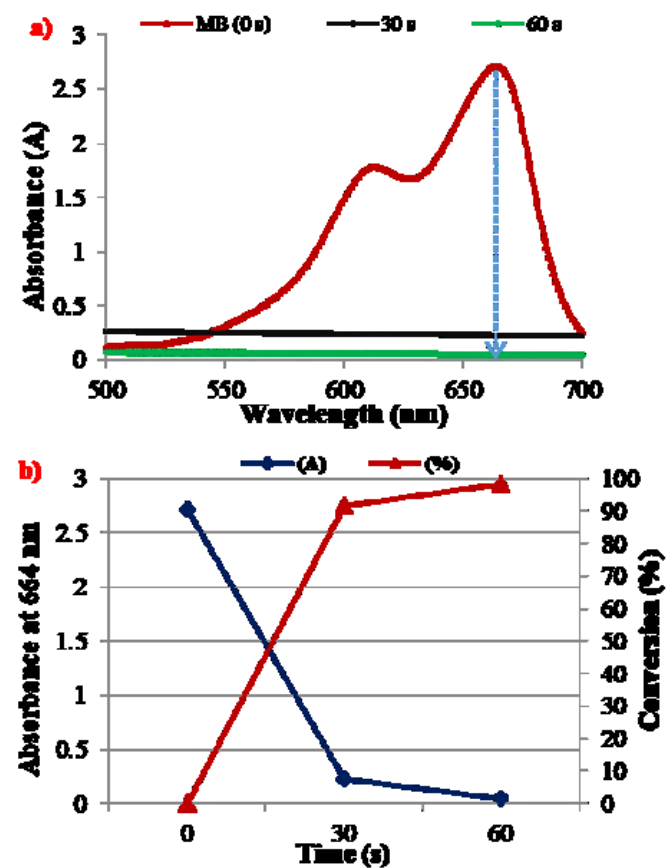

Figure-8. Time-dependent UV-vis absorption spectra of the methylene blue $\left(5.0 \times 10^{-5} \mathrm{M}\right)$ reduced by $\mathrm{NaBH}_{4}$ catalyzed by the M1 nanocomposite (a) UV-vis spectra, b) Absorbance-Conversion curve). 


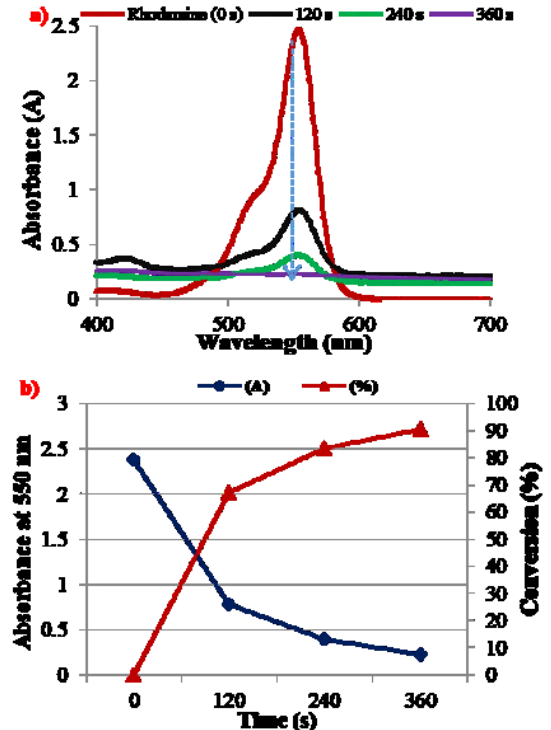

Figure-9. Time-dependent UV-vis absorption spectra of the Rhodamine B (10 ppm) reduced by $\mathrm{NaBH}_{4}$ catalyzed by the $\mathbf{M}_{\mathbf{1}}$ nanocomposite (a) UV-vis spectra, b) Absorbance-Conversion curve).
Summarize, the kinetic equation for the reduction of nitrophenols and dyes can be represented as $\ln \left(\mathrm{C}_{t} / \mathrm{C}_{0}\right)=$ $-k t$, where $t$ is time for the catalytic reaction and, $k$ is the apparent first-order rate constant $\left(\mathrm{s}^{-1}\right)$ in Table-1. Moreover, the $\mathrm{k}^{\prime}=\mathrm{k} / \mathrm{M}$ parameter $(\mathrm{M}$ : the amount of the catalyst) is introduced for quantitative comparison and the parameter is defined as the ratio of the rate constant $k$ to the weight of the catalyst added [24]. In Table-1, the catalytic activity rate constant parameters were compared for the nanocomposite $\left(\mathbf{M}_{1}\right)$.

The reaction rates of nitrophenols with catalyst $\mathrm{M}_{1}$ at $300 \mathrm{~s}$ were recorded as $6.78 \mathrm{E}-03 \mathrm{~s}^{-1}(2-\mathrm{NP})$ and $1.28 \mathrm{E}$ $02 \mathrm{~s}^{-1}$ (4-NP) and for dyes, the rates were founded as $6.80 \mathrm{E}-02 \mathrm{~s}^{-1}$ at $60 \mathrm{~s}$ (M. Blue) and $6.58 \mathrm{E}-03 \mathrm{~s}^{-1}$ at $360 \mathrm{~s}$ (Rhodamine B).

A mixture of 4-nitrophenol, rhodamine $\mathrm{B}$, and methylene blue substrates was prepared to better demonstrate the effectiveness of the catalyst, and their reduction with the $\mathbf{M}_{1}$ catalyst was observed. In the results, after 300 seconds, the $\mathbf{M}_{1}$ catalyst was able to reduce all three substrates $>90 \%$, simultaneously (Figure10).

Table 1. The catalytic efficiency rate constant of $\mathbf{M}_{\mathbf{1}}$ catalysts.

\begin{tabular}{|c|c|c|c|c|c|c|}
\hline Substrate & \multicolumn{3}{|c|}{$k\left(s^{-1}\right)^{a}$} & \multicolumn{3}{|c|}{$\mathbf{k} / \mathbf{M}\left(\mathrm{s}^{-1} \mathrm{~g}^{-1}\right)^{\mathbf{b}}$} \\
\hline \multirow{2}{*}{ 2-NP } & $30 s$ & $90 s$ & $300 s$ & $30 s$ & $90 \mathrm{~s}$ & $300 s$ \\
\hline & 1.39E-02 & $1.46 \mathrm{E}-02$ & 6.78E-03 & $5.57 \mathrm{E}+00$ & $5.83 \mathrm{E}+00$ & $2.71 \mathrm{E}+00$ \\
\hline \multirow{2}{*}{ 4-NP } & $30 \mathrm{~s}$ & $90 \mathrm{~s}$ & $300 s$ & $30 s$ & $90 s$ & $300 s$ \\
\hline & 2.39E-02 & 9.95E-03 & $1.28 \mathrm{E}-02$ & $9.58 \mathrm{E}+00$ & $3.98 \mathrm{E}+00$ & $5.12 \mathrm{E}+00$ \\
\hline \multirow{2}{*}{ M. Blue } & $30 s$ & & $60 s$ & $30 s$ & & $60 \mathrm{~s}$ \\
\hline & $8.26 \mathrm{E}-02$ & & $6.80 \mathrm{E}-02$ & $3.30 \mathrm{E}+01$ & & $2.72 \mathrm{E}+01$ \\
\hline \multirow{2}{*}{ Rhodamine B } & $120 \mathrm{~s}$ & $240 s$ & $360 s$ & $120 \mathrm{~s}$ & $240 s$ & $360 s$ \\
\hline & $9.31 \mathrm{E}-03$ & $7.52 \mathrm{E}-03$ & $6.58 \mathrm{E}-03$ & $3.72 \mathrm{E}+00$ & $3.01 E+00$ & $2.63 E+00$ \\
\hline
\end{tabular}

${ }^{a}$ The reaction rate constant. ${ }^{\mathrm{b}}$ The reaction rate constant per total weight of tested catalyst $(2.5 \mathrm{mg})$

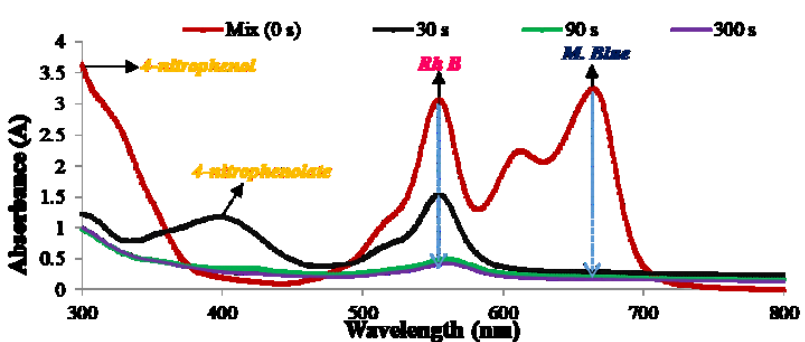

Figure-10. Time-dependent UV-vis absorption spectra of 4-NP, Rh B, and M. Blue reduced by $\mathrm{NaBH}_{4}$ catalyzed by the $\mathbf{M}_{1}$ nanocomposite.

To determine the efficiency of the catalyst, a reusability study was carried out. The 4-nitrophenol was chosen as the model substrate and the Cu/Ligand@Fullerene $\left(\mathbf{M}_{1}\right)$ catalyst was used 5 times in the same reaction (Figure11). The reusability results $(\mathrm{I}-\mathrm{V})$ were recorded as $97.9 \%, 97.7 \%, 97.7 \%, 97.3 \%$, and $87.3 \%$, respectively. According to the reusability results, the efficiency of the catalyst was determined to be good and suitable for economic purposes.

The production costs are as important as the catalytic activities of the catalysts produced. As is known, the copper nanoparticles can be manufactured in many easy routes. At the same time, their catalytic activities can be increased by creating hybrids with many materials.

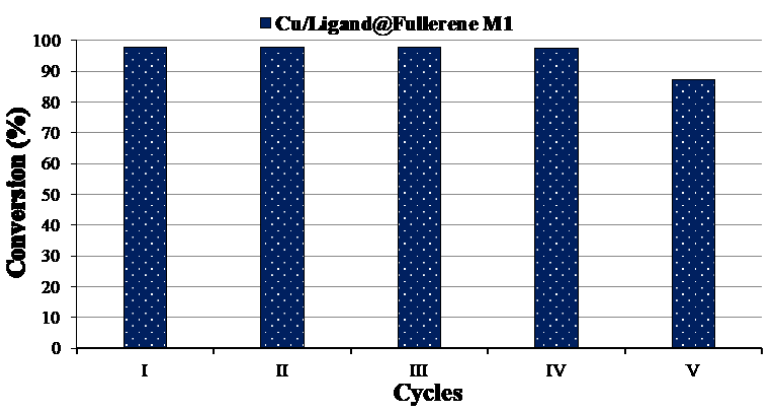

Figure-11. Catalytic activities of Cu/Ligand@Fullerene (M) nanocomposite in 5 cycles. 
It can be said that the catalytic activity results in this study are at a good level compared to their peers in the literature (Table-2).

Considering the substrate concentrations in the solution, it can be said that the $\mathbf{M}_{1}$ nanocomposite shows the highest activity with 2-nitrophenol. However, the good catalytic results with $\mathbf{M}_{1}$ nanocomposite were obtained for other substrates and it is well known that dyes such as nitrophenols and methylene blue, especially Rhodamine B, are serious environmental pollutants. The removal of these compounds is very important, and, in this study, it was determined that a material that can be easily produced reduces these harmful compounds with high

Table 2. The comparative data of the reduction reactions.

\begin{tabular}{|c|c|c|c|c|}
\hline Catalyst & Substrate & Time (s) & $\begin{array}{c}\text { Catalytic rate constant " } k \text { " } \\
\left(\mathrm{s}^{-1}\right)\end{array}$ & References \\
\hline AG-CuO hydrogel & 2-Nitrophenol & 420 & $5.11 \mathrm{E}-03$ & {$[25]$} \\
\hline $\mathrm{Cu}^{0}$-NPANI-ZrSiO 4 & 2-Nitrophenol & 120 & $9.73 \mathrm{E}-03$ & {$[26]$} \\
\hline Cu/Ligand@Fullerene & 2-Nitrophenol & 300 & $6.78 \mathrm{E}-03$ & Present study \\
\hline CuO NPs & 4-Nitrophenol & 360 & $8.80 \mathrm{E}-02$ & {$[11]$} \\
\hline Cu@Pd NPs & 4-Nitrophenol & 720 & $5.80 \mathrm{E}-03$ & [27] \\
\hline Cu/Ligand@Fullerene & 4-Nitrophenol & 300 & $1.28 \mathrm{E}-02$ & Present study \\
\hline CuVOS-3 & M. Blue & 480 & $1.21 \mathrm{E}-02$ & {$[28]$} \\
\hline $\mathrm{C} @ \mathrm{Cu}$ & M. Blue & 60 & $8.90 \mathrm{E}-2$ & [29] \\
\hline Cu/Ligand@Fullerene & M. Blue & 60 & $6.80 \mathrm{E}-02$ & Present study \\
\hline CuVOS-3 & Rhodamine B & 480 & $1.55 \mathrm{E}-02$ & {$[28]$} \\
\hline $\begin{array}{l}\text { TEA1.5-G150 }^{\circ} \mathrm{C}- \\
\mathrm{CuO}^{-}{ }^{\circ} 0^{\circ} \mathrm{C}\end{array}$ & Rhodamine B & 210 & $4.70 \mathrm{E}-02$ & {$[30]$} \\
\hline Cu/Ligand@Fullerene & Rhodamine B & 360 & $6.58 \mathrm{E}-03$ & Present study \\
\hline
\end{tabular}

\section{Conclusion}

Herein, we have reported the fabrication of $\mathrm{N}-(3-((2-$ hydroxybenzylidene)amino)phenyl)benzamide ligand and $\mathrm{Cu} /$ Ligand@Fullerene nanocomposite $\left(\mathbf{M}_{\mathbf{1}}\right)$ nanocomposite, and the $\mathbf{M}_{1}$ nanocomposite was tested as a catalyst in the reduction of nitrophenols (2-NP, 4NP) and organic dyes (M. Blue, Rhodamine B). The fabricated nanocomposite $\mathbf{M}_{\mathbf{1}}$ is highly efficient in the reduction of nitrophenols (2-NP, 4NP) ( $>90 \%$ catalytic conversion in $5 \mathrm{~min}$.), M. blue $(>90 \%$ catalytic conversion in $0.5 \mathrm{~min}$.), and Rhodamine B (>90\% catalytic conversion in $6 \mathrm{~min}$.) at ambient temperature. In this study, the advantages such as the ease of synthesis, high activity results, and easy workability of the produced material came to the fore.

\section{Author's Contributions}

Serkan Dayan: Drafted and wrote the manuscript, performed the experiment and result analysis.

\section{Ethics}

There are no ethical issues after the publication of this manuscript.

\section{References}

1. Xu, YL, Shi, XF, Hua, R, Zhang, R, Yao YJ, Zhao, B, Liu, T, Zheng, JZ, Lu, G. 2020. Remarkably catalytic activity in reduction of 4-nitrophenol and methylene blue by $\mathrm{Fe}_{3} \mathrm{O}_{4} @ \mathrm{COF}$ supported noble metal nanoparticles. Applied Catalysis B: Environmental; 260

2. Yang, YT, Wang, TA, Jing, XF, Zhu, GS. 2019. Phosphine-based porous aromatic frameworks for gold nanoparticle immobilization with superior catalytic activities. Journal of Materials Chemistry A; 7(16): 10004-10009.

3. Dayan, S, Arslan, F, Ozpozan, NK. 2015. Ru(II) impregnated $\mathrm{Al}_{2} \mathrm{O}_{3}, \quad \mathrm{Fe}_{3} \mathrm{O}_{4}, \quad \mathrm{SiO}_{2}$ and N-ecoordinate ruthenium(II) arene complexes: Multifunctional catalysts in the hydrogenation of nitroarenes and the transfer hydrogenation of aryl ketones. Applied Catalysis B: Environmental; 164: 305-315.

4. Dell'Anna, MM, Intini S, Romanazzi, G, Rizzuti, A, Leonelli, C, Piccinni, F, Mastrorilli, P. 2014. Polymer supported palladium nanocrystals as efficient and recyclable catalyst for the reduction of nitroarenes to anilines under mild conditions in water. Journal of Molecular Catalysis A; 395: 307-314.

5. Hu, XW, Long, Y, Fan, MY, Yuan, M, Zhao, H, Ma, JT, Dong, ZP. 2019. Two-dimensional covalent organic frameworks as selftemplate derived nitrogen-doped carbon nanosheets for ecofriendly metal-free catalysis. Applied Catalysis B: Environmental; 244: $25-35$.

6. Shokouhimehr, M, Kim, T, Jun, SW, Shin, K, Jang, Y, Kim, BH, Kim, J, Hyeon, T. 2014. Magnetically separable carbon nanocomposite catalysts for efficient nitroarene reduction and Suzuki reactions. Applied Catalysis A: General; 476: 133-139.

7. Das, P, Ghosh, S, Baskey, M. 2019. Heterogeneous catalytic reduction of 4-nitroaniline by $\mathrm{RGO}-\mathrm{Ni}$ nanocomposite for water resource management. Journal of Materials Science: Materials in Electronics; 30: 19731-19737.

8. Qu, YM, Chen, T. 2020. Fullerene derivative supported Ni for hydrogenation of nitrobenzene: Effect of functional group of fullerene derivative. Chemical Engineering Journal; 382: 122911.

9. Liu, Q, Tadrent, S, Proust, C, Gomez, F, Khelfa, A, Luart, D, Len, C. 2020. Theoretical analysis of the "green" synthesis of 
aniline by reduction of nitrobenzene. Chemical Engineering Science; 211: 115275.

10. Du, JT, Shi, J, Sun, Q, Wang, D, Wu, H, Wang, JX, Chen, JF. 2020. High-gravity-assisted preparation of aqueous dispersions of monodisperse palladium nanocrystals as pseudohomogeneous catalyst for highly efficient nitrobenzene reduction. Chemical Engineering Journal; 382: 122883.

11. Baloch, GNL, Mahesar, SA, Khan, S, Niisar, J, Sherazi, STH. 2020. Ranolazine-functionalized $\mathrm{CuO}$ NPs: efficient homogeneous and heterogeneous catalysts for reduction of 4 nitrophenol, Turkish Journal of Chemistry; 44 (1): 168-179.

12. Dayan, S, Altinkaynak, C, Kayaci, N, Dogan, SD, Özdemir, N, Ozpozan, NK. 2020. Hybrid nanoflowers bearing tetraphenylporphyrin assembled on copper(II) or cobalt(II) inorganic material: A green efficient catalyst for hydrogenation of nitrobenzenes in water. Applied Organometallic Chemistry; 34 (3): e5381.

13. Hira, SA, Nallal, M, Park, KH. 2019. Fabrication of PdAg nanoparticle infused metal-organic framework for electrochemical and solution-chemical reduction and detection of toxic 4nitrophenol. Sensors and Actuators B: Chemical; 298: 126861.

14. Shahini, P, Ashkarran, AA. 2018. Immobilization of plasmonic Ag-Au NPs on the $\mathrm{TiO}_{2}$ nanofibers as an efficient visible-light photocatalyst. Colloids and Surfaces A; 537: 155-162.

15. Mahnaz, F, Mostafa-Al-Momin, M, Rubel, M, Ferdous, M, Azam, MS. 2019. Mussel-inspired immobilization of Au on bare and graphene-wrapped $\mathrm{Ni}$ nanoparticles toward highly efficient and easily recyclable catalysts. RSC Advances; 9 (52): 30358 30369.

16. Li, CX, Wang, JK, Jiang, $\mathrm{ZH}$, Hu, PG. 2015. $\mathrm{Co} / \mathrm{Cu}_{2} \mathrm{O}$ assisted growth of graphene oxide on carbon nanotubes and its water splitting activities. New Journal of Chemistry; 39 (6): 4562-4567.

17. Jiang, JW, Lim, YS, Park, S, Kim, SH, Yoon, S, Piao, L. 2017. Hollow porous $\mathrm{Cu}$ particles from silica-encapsulated $\mathrm{Cu}_{2} \mathrm{O}$ nanoparticle aggregates effectively catalyze 4-nitrophenol reduction. Nanoscale; 9 (11): 3873-3880

18. Taherinia, Z, Ghorbani-Choghamarani, A. 2019. Cu(I)-PNF, an organic-based nanocatalyst, catalyzed $\mathrm{C}-\mathrm{O}$ and C-S crosscoupling reactions. Canadian Journal of Chemistry; 97 (1): 4652.

19. Singh, G, Rani, S, Arora, A, Sanchita, Duggal, H, Mehta, D. 2017. Organic-inorganic nano-hybrid decorated by copper (II) incarceration: A versatile catalytic assembly for the swift reduction of aromatic nitro and dye compounds. Molecular Catalysis; 431: 15-26.

20. Ahmadi, A, Sedaghat, T, Motamedi, H, Azadi. R. 2020. Anchoring of $\mathrm{Cu}$ (II)-Schiff base complex on magnetic mesoporous silica nanoparticles: catalytic efficacy in one-pot synthesis of 5 -substituted-1H-tetrazoles, antibacterial activity evaluation and immobilization of alpha-amylase. Applied Organometallic Chemistry; 34 (5) e5572.

21. Tahmasbi, L, Sedaghat, T, Motamedi, H, Kooti, M. 2018 Mesoporous silica nanoparticles supported copper(II) and nickel(II) Schiff base complexes: Synthesis, characterization, antibacterial activity and enzyme immobilization. Journal of Solid State Chemistry; 258: 517-525.

22. Ramu, VG, Bordoloi, A, Nagaiah, TC, Schuhmann, W, Muhler, M, Cabrele, C. 2012. Copper nanoparticles stabilized on nitrogendoped carbon nanotubes as efficient and recyclable catalysts for alkyne/aldehyde/cyclic amine A(3)-type coupling reactions. Applied Catalysis A: General; 431: 88-94.
23. Dayan, S, Kayaci, N, Dayan, O, Ozdemir, N, Ozpozan, NK. 2020. Nickel (II) complex $\left[\mathrm{NiCl}_{2}(\mathrm{DMF})_{2} \mathrm{~L}_{2}\right]$ bearing diaminobenzene and sulfonamide: Crystal structure and catalytic application in the reduction of nitrobenzenes. Polyhedron; 175: 114181.

24. Baghbamidi, SE, Hassankhani, A, Sanchooli, E, Sadeghzadeh, SM. 2018. The reduction of 4-nitrophenol and 2-nitroaniline by palladium catalyst based on a $\mathrm{KCC}-1 / \mathrm{IL}$ in aqueous solution. Applied Organometallic Chemistry; 32 (4): e4251.

25. Kamal, T. 2019. Aminophenols formation from nitrophenols using agar biopolymer hydrogel supported $\mathrm{CuO}$ nanoparticles catalyst. Polymer Testing; 77: 105896

26. Mahmoud, ME, Amira, MF, Abouelanwar, ME, Seleim, SM. 2020. Catalytic reduction of nitrophenols by a novel assembled nanocatalyst based on zerovalent copper-nanopolyanilinenanozirconium silicate. Journal of Molecular Liquids; 299: 112192 .

27. Li, ML, Chen, GF. 2013. Revisiting catalytic model reaction pnitrophenol/NaBH4 using metallic nanoparticles coated on polymeric spheres, Nanoscale; 5 (23):11919-11927.

28. Sun, HZ, Zelekew, OA, Chen, $X Y$, Guo, YB, Kuo DH, Lu, QX, Lin, JG. 2019. A noble bimetal oxysulfide CuVOS catalyst for highly efficient catalytic reduction of 4-nitrophenol and organic dyes. RSC Advances; 9 (55): 31828-31839.

29. Ahsan, MA, Jabbari, V, El-Gendy, AA, Curry, ML, Noveron, JC. 2019. Ultrafast catalytic reduction of environmental pollutants in water via MOF-derived magnetic $\mathrm{Ni}$ and $\mathrm{Cu}$ nanoparticles encapsulated in porous carbon. Applied Surface Science; 497: 143608.

30. Liang, $X$, Chen, XW, Xiang, ZL, Yan, R, Xi, H, Bian, T, Zhang, JJ, Zhao, JX, Cai, QH, Wang, HX. 2018. Design and synthesis of surface-controlled $\mathrm{CuO}_{\mathrm{x}} / \mathrm{rGO}$ nanocomposites with unusually high efficiency in catalytic conversion of organic reactants in the presence of $\mathrm{NaBH}_{4}$. Applied Surface Science; 459: 716-722. 